\title{
Coherent Doppler Wind Lidar Technology for Space- Based Wind Measurements Including SPARCLE
}

\author{
Michael J. Kavaya \\ Mail Code HR20 \\ NASA Marshall Space Flight Center \\ Huntsville, AL 35812 \\ $256-922-5803$ \\ michael.kavaya@msfc.nasa.gov \\ Upendra N. Singh \\ Mail Code 474 \\ NASA Langley Research Center \\ Hampton, VA 23681 \\ 757-864-1570 \\ u.n.singh@larc.nasa.gov
}

It has been over 30 years since coherent lidar systems first measured wind velocity ${ }^{1}$, and over 20 years since the "ultimate application" of measuring Earth's winds from space was conceived. ${ }^{2}$ Coherent or heterodyne optical detection involves the combination (or mixing) of the returned optical field with a local oscillator (LO) laser's optical field on the optical detector. This detection technique yields the benefits of dramatically improved signal-to-noise ratios; insensitivity to detector noise, background light, and multiply scattered light; reduction of the returned signal's dynamic range; and preservation of the optical signal spectrum for electronic and computer processing ${ }^{3,4}$. Note that lidar systems are also referred to as optical radar, laser radar, and LADAR systems.) Many individuals, agencies, and countries have pursued the goal 
Kavaya and Singh, Invited I-00009, Coherent Doppler Wind Lidar Technology for Space-Based ...

of space-based wind measurements through technology development, experiments, field campaigns, and studies

For most of these years, the mature and powerful $\mathrm{CO}_{2}$ laser has been the leading contender for coherent lidar wind measurements including the space application. However, during the 1980 s, solid state laser technology made rapid advances. This technology promised to provide long life, small size, and high electrical efficiency; which was a good match to the demands of space flight, and the move within NASA to smaller sensors. In 1993, a joint program to develop solid state laser-based coherent lidar technology for space-based wind measurement was begun by NASA's Marshall Space Flight Center (MSFC), NASA's Langley Research Center (LaRC), and NASA's Jet Propulsion Laboratory (JPL). Figure 1 shows a schematic of a coherent Doppler wind lidar (CDWL) system. LaRC assumed responsibility for the pulsed transmitter laser, items 1 and 2 in Figure 1. JPL took responsibility for development of the tunable laser, item 8, which is required to cancel the large Doppler shifts of backscattered laser light when the lidar is moving at orbital speeds. MSFC was responsible for the development of the telescope, item 5, the scanner, item 6 , the heterodyne detection subsystem, item 10, and specialized technologies not explicitly shown in Figure 1 such as misalignment correction, autonomous operation, pointing knowledge, and lidar system efficiency enhancing technologies. MSFC also managed the program. Personnel at the University of Alabama Center for Applied Optics (UAH/CAO) have performed much of the MSFC effort.

The joint technology development effort was successful ${ }^{6-9}$, and the SPAce Readiness Coherent Lidar Experiment (SPARCLE) was awarded to the MSFC/LaRC/JPL team in 1997. The SPARCLE Mission will fly a CDWL system on the Space Shuttle in 2001. The mission goals are: 1) to demonstrate that the technology and technique can measure tropospheric vector winds from space, 2) to confirm and update CDWL performance models for accurate prediction of proposed future missions, and 3) to characterize the earth and atmosphere for optimum selection of future mission instrument and operational parameters. SPARCLE is the second earth observing (EO2) mission of NASA's New Millennium Program (NMP), managed by JPL and GSFC. The SPARCLE mission will represent the first space-based: 1) pulsed coherent detection lidar, 2) scanning lidar, 3) programmable frequency-agile optical receiver, 4) laser wind measurement, 5) tropospheric wind profiling, and 6) vector wind profiling. 
Kavaya and Singh, Invited I-00009, Coherent Doppler Wind Lidar Technology for Space-Based ...

The NASA team has a roadmap of missions following SPARCLE that will culminate in an NPOESS (National Polar-orbiting Operational Environmental Satellite System) operational wind profiling sensor. In order to accomplish this, the MSFC/LaRC/JPL team needs to continue to advance the CDWL technology in time to satisfy each mission. Some of the specifications for the final mission (as well as the specifications for SPARCLE) are envisioned to be:

$\begin{array}{ll}\text { Mission duration: } & 7 \text { years (14 days) } \\ \text { Pulsed laser energy: } & 2 \mathrm{~J}(0.1 \mathrm{~J}) \\ \text { Pulse repetition frequency: } & 12.5 \mathrm{~Hz}(6 \mathrm{~Hz}) \\ \text { Pulsed laser wallplug efficiency: } & 5 \%(<1 \%) \\ \text { LO laser tuning: } & \pm 5.2 \mathrm{GHz}( \pm 4.5 \mathrm{GHz}) \\ \text { Aperture diameter } & 1 \mathrm{~m}(0.25 \mathrm{~m}) \\ \text { Scanner } & \text { Diffractive, } 45-\text { deg. nadir angle (Silicon wedge, 30-deg.) } \\ \text { Lidar system efficiency } & 10 \%(2 \%) \\ \text { Alignment maintenance } & \text { Active/passive combination (passive) } \\ \text { Pointing knowledge } & \text { Star tracker/INS/GPS/lidar surface returns combination (no } \\ \end{array}$

1. A. V. Jelalian and R. M. Huffaker, "Application of Laser Doppler Techniques to Turbulent Velocity Measurement. Part II. Laser Doppler Techniques for Remote Wind Velocity Measurements," Specialist Conference on Molecular Radiation and its Application to Diagnostic Techniques, NASA TM X-53711, 345-358, Huntsville, AL, 5-6 Oct. 1967.

2. R. M. Huffaker, D. W. Beran, and C. G. Little, "Pulsed Coherent Lidar Systems for Airborne and Satellite Based Wind Field Measurement," Proc. $7^{\text {th }}$ Conf. Aerosp. And Aeronaut. Meteor., 318-324, AMS, 1976.

3. R. T. Menzies, "Laser Heterodyne Detection Techniques," Ch. 7 in "Laser Monitoring of the Atmosphere, E. D. Hinkley, editor, Springer-Verlag, 1976.

4. R. H. Kingston, "Detection of Optical and Infrared Radiation," Springer-Verlag, 1978.

5. For a list of studies, refer to http://wwwghcc.msfc.nasa.gov/sparcle/sparcle bibliography.html . 
Kavaya and Singh, Invited I-00009, Coherent Doppler Wind Lidar Teclınology for Space-Based ...

6. A. Ahmad, C. Feng, and A. Amzajerdian, "Design and Fabrication of a Compact Lidar Telescope," Proc. SPIE Vol. 2832, pp. 34-42, Denver, CO (4-9 Aug. 1996).

7. U. N. Singh, N. P. Barnes, J. A. Williams-Byrd, G. E. Lockard, E. A. Modlin, J. Yu, and M. Petros, "Injection Seeded, Room Temperature, Diode Pumped Ho:Tm:YLF Laser With Output Energy Of 600 mJ At $10 \mathrm{~Hz}$," paper AWCl, Proc. Advanced Solid State Lasers Conference, Optical Society of America, pp. 322-324, Coeur D'Alene, ID (2-4 Feb. 1998).

8. M. J. Kavaya and G. D. Emmitt, "The Space Readiness Coherent Lidar Experiment (SPARCLE) Space Shuttle Mission," Proc. SPIE Vol. 3380, pp. 2-11, Conference on Laser Radar Technology and Applications III, 12th Annual International Symposium on Aerospace/Defense Sensing, Simulation, and Controls, AeroSense, Orlando, FL (14-16 April 1998).

9. H. Hemmati, C. Esproles, and R. T. Menzies, "Frequency-Stabilized Diode-Pumped Tm,Ho:YLF Local Oscillator With \pm 4 GHz Of Tuning Range," Proc. SPIE Vol. 3380, pp. 75-79, Conference on Laser Radar Technology and Applications III, 12th Annual International Symposium on Aerospace/Defense Sensing, Simulation, and Controls, AeroSense, Orlando, FL (14-16 April 1998). 
Kavaya and Singh, Invited I-00009, Coherent Doppler Wind Lidar Technology for Space-Based ...

\section{CFE1 FIGURE CAPTIONS}

Fig. 1 Coherent Doppler Wind Lidar System 
Kavaya and Singh, Invited I-00009, Coherent Doppler Wind Lidar Technology for Space-Based ...

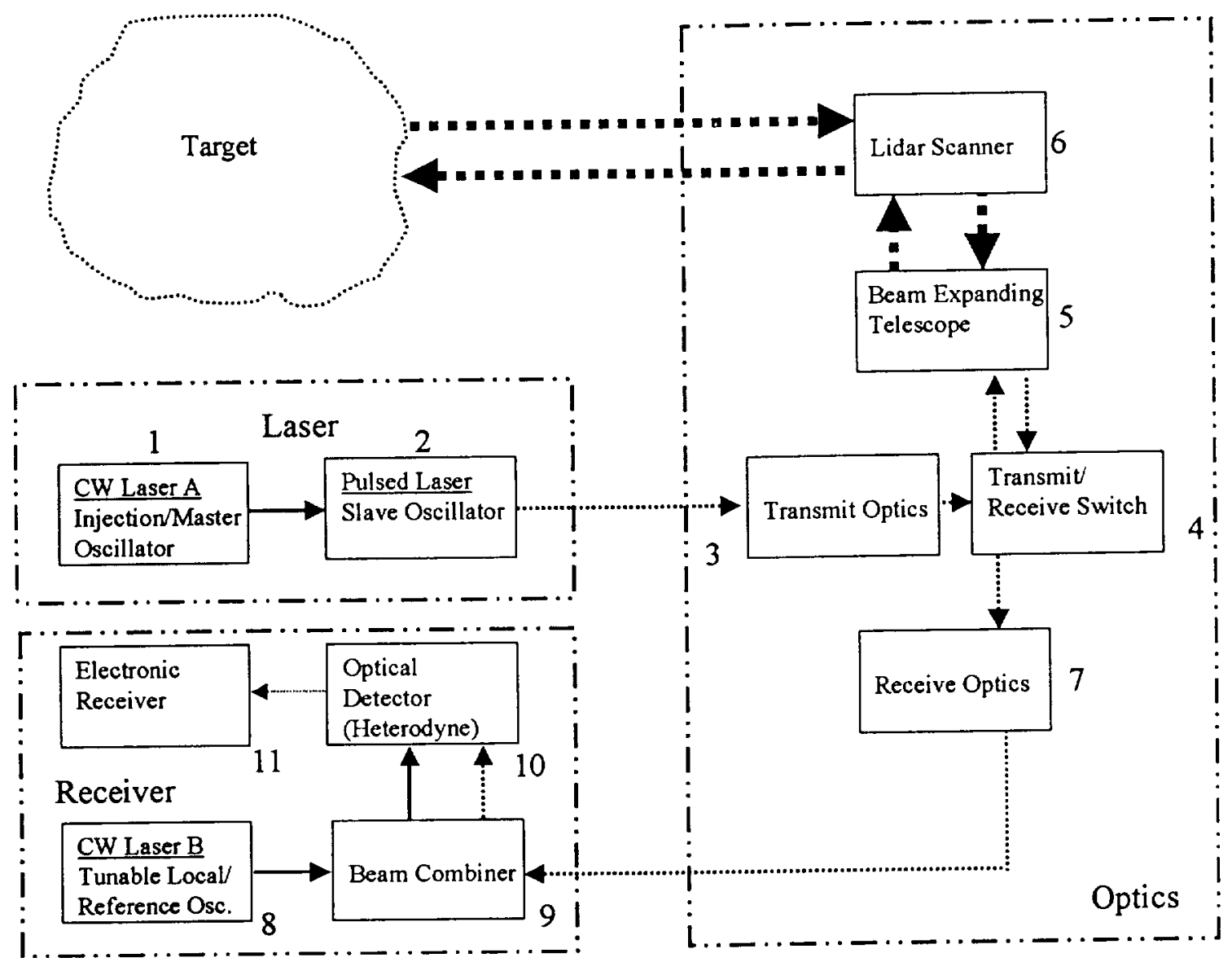

